doi:

M.P. GORISHNYI, A.B. VERBITSKY

Institute of Physics, Nat. Acad. of Sci. of Ukraine

(46, Prosp. Nauky, Kyiv 03680,Ukraine; e-mail: gorishny@iop.kiev.ua)

\title{
STRUCTURAL, OPTICAL, AND PHOTOVOLTAIC PROPERTIES PACS 78.40.Me, 73.50.Pz OF TETRACENE THIN FILMS
}

\begin{abstract}
The structure, absorption spectra, and photovoltaic response of tetracene (Tc) thin films 120 and $200 \mathrm{~nm}$ in thickness deposited in a vacuum of $6.5 \mathrm{MPa}$ onto different substrates at room temperature have been studied. The photovoltaic response is measured by the method of capacitor cell. It is found that island films are formed on glass and quartz substrates, whereas solid polycrystalline films on copper ones, which is a result of the different interaction energies of Tc molecules with one another and with substrate molecules, molecules of ITO layers, and carbon atoms on the substrate surface. In quasi-amorphous films at a temperature of 4.2 K, excited molecules are deformed stronger as compared to those in polycrystalline films and free molecules at $300 \mathrm{~K}$.

The photo-emf $V_{\mathrm{f}}$ at the front (illuminated) free surfaces of Tc films is negative in the spectral interval of 1.637-3.258 eV, which testifies to the hole photoconductivity in the films. The photo-emf $V_{\mathrm{r}}$ at the rear surface of 120-nm Tc films (illumination through the ITO electrode, which directly contacted with the Tc film) changed its sign in the spectral intervals of 2.1932.494 and 2.927-3.153 eV as the oxygen concentration in the measuring cell decreased, which testifies to a change of the energy band bending in the Tc films near their rear and front (free) surfaces.

Ke ywords: tetracene thin films, $\mathrm{Al}-\mathrm{Tc}-\mathrm{Au}$ heterostructures, photovoltaic response.
\end{abstract}

\section{Introduction}

Tetracene (Tc) is a polycyclic aromatic hydrocarbon classed to the acene series. Its molecule $\mathrm{C}_{18} \mathrm{H}_{12}$ consists of four benzene rings connected in line. Tc is an organic high-resistance semiconductor of the $p$ type with a wide energy gap $E_{g} \geq 3.0 \mathrm{eV}$ [1]. In $\mathrm{Al}-\mathrm{Tc}-\mathrm{Au}$ heterostructures, the direct dark current is confined by a space charge and is a result of the hole injection from the positively charged $\mathrm{Au}$ electrode [2]. The magnitudes of short-circuit photocurrent $J_{\mathrm{sc}}$ and open-circuit voltage $V_{\mathrm{oc}}$ in those heterostructures depend on the material of the illuminated electrode and the illumination direction $[2,3]$. The photokinetic response of Tc single crystals demonstrates the fast and slow components with opposite signs. The spectrum of the fast component correlates with the absorption spectrum, and the slow component manifests itself more strongly in the interval of weak crystal absorption [4].

(c) M.P. GORISHNYI, A.B. VERBITSKY, 2016
Tc is applied as an active medium in organic fieldeffect transistors (OFETs) [5-10] and organic lightemitting diodes (OLEDs) [11-15].

The characteristics of solar cells (SCs) created on the basis of multilayer heterostructures with an active $\mathrm{Tc} / \mathrm{C}_{60}$ (fullerene) heterojunction, which can be found in the literature, are different. This fact is associated with different structures of those SCs and different illumination conditions. The best results (the efficiency $\eta=2.3 \%$ and $V_{\mathrm{oc}}=0.58 \mathrm{~V}$ ) were obtained under standard illumination conditions (AM1.5, $100 \mathrm{~mW} / \mathrm{cm}^{2}$ ). The Tc films were found to be composed of submicronic grains with a rough surface, which increases the effective area of the $\mathrm{Tc} / \mathrm{C}_{60}$ surface contact for the exciton diffusion and reduces the recombination rate of photo-generated charge carriers [16]. The thermal annealing of those heterostructures increases their $\eta, V_{\mathrm{oc}}$, and filling factor $\mathrm{FF}$, which is associated with the growth of both the crystallite dimensions in Tc films and the hole mobility [17]. If thin $\mathrm{C}_{60}$ films are sputtered in vacuum on Tc single crystals, the efficiency of those heterostruc-

ISSN 2071-0186. Ukr. J. Phys. 2016. Vol. 61, No. 1 
tures turns out substantially lower: $\eta=0.34 \%$ and $V_{\mathrm{oc}}=0.57 \mathrm{~V}[18]$.

Multilayer heterostructures with an active $\mathrm{Tc} / \mathrm{ZnF}_{16} \mathrm{Pc}$ (zinc fluoro-phthalocyanine) heterojunction effectively absorb light in a wide spectral interval (350-900 nm). At their illumination with a xenon lamp (AMO, $20 \mathrm{~mW} / \mathrm{cm}^{2}$ ), the following characteristics were obtained: $J_{\mathrm{sc}}=18 \mu \mathrm{A} / \mathrm{cm}^{2}$, $V_{\mathrm{oc}}=0.57 \mathrm{~V}, \mathrm{FF}=0.25$, and $\eta=0.01 \%$. Low values of those parameters are a result of a high series resistance of the cells that arises owing to non-optimal thicknesses of the $\mathrm{Tc}$ and $\mathrm{ZnF}_{16} \mathrm{Pc}$ films. Moreover, oxygen in air diminishes the conductivity of $\mathrm{ZnF}_{16} \mathrm{Pc}$ [19].

The literature data presented above testify that the photo-electric properties of Tc films and single crystals are intensively studied in order to use Tc as an active medium in OFETs, OLEDs, and SCs, as well as to improve the parameters of those devices. Our analysis of literature data showed that the origin of the photovoltaic response in condensed Tc has been studied insufficiently. In this work, the structure, absorption spectra, and photovoltaic properties of Tc films of submicronic thickness are analyzed. In addition, the energy of intermolecular interaction in Tc films and crystals is estimated.

\section{Experimental Technique}

Thin Tc films were thermally sputtered in a vacuum of $6.5 \mathrm{mPa}$ onto quartz, glass, and copper substrates. The thicknesses of those films were measured using a MII-4 interference thickness meter. Absorption spectra were registered on a Perkin Elmer Lambda $25 \mathrm{uv} /$ vis spectrophotometer at a spectral width of $1 \mathrm{~nm}$ and at room temperature. The spectral dependences of the photo-emf $V$ were measured using the method of capacitor cell, which was described in work [20]. The structure of Tc films was studied using an optical microscope Carl Zeiss Pernal Interphako and an electron scanning microscope JSM-35 (IEOL, Japan).

\section{Experimental Results}

The optical microscopy researches demonstrated a granular structure of Tc films (see column $a$ in Table 1). The brightness of grains (crystallites) changed if the polarizer was rotated around the vertical axis of the microscope, which testifies to different orienta- tions of the optical axes of grains with respect to the substrate plane.

The electron scanning microscopy revealed that the surface density of thin crystallites grew in the direction from the boundary to the center of a Tc film, and the crystallite length did not exceed $1 \mu \mathrm{m}$ (column $b$ ). The structure of the central sections of Tc films was island-like, i.e. a spatial network of crystallites connected with one another arises in the course of crystallization. Dark sections in the figure (network cells) correspond to the substrate surface covered with a thin carbon layer, where the crystallization was absent. The structure of Tc films on glass substrates with a conducting ITO layer was found to be similar to that on substrates covered with a carbon layer (columns $b$ and $c$ ). Tc films on copper substrates were continuous (column $d$, the upper figure). Here, light lines mark the contours of sections with different thicknesses and shapes. Those sections smoothly transform into one another, and the longitudinal dimensions for the majority of them are close to $1 \mu \mathrm{m}$. Submicronic crystallites were formed in some sections on the surface of the initial Tc layer (column $d$, the lower figure). Dark lines in the lower figure mark defects of the copper substrate.

The analysis of the absorption spectra of Tc films with various thicknesses $d$ (Fig. 1) shows that, in the interval from 1.6 to $3.5 \mathrm{eV}$, where $\alpha \leq 3 \times 10^{4} \mathrm{~cm}^{-1}$, the spectral distribution of the absorption coefficient $\alpha$ does not depend on $d$ in the interval $120 \mathrm{~nm} \leq$ $\leq d \leq 200 \mathrm{~nm}$, i.e. the Bouguer-Lampert-Beer law is obeyed. This law is violated at $\alpha>3 \times 10^{4} \mathrm{~cm}^{-1}$

\section{Table 1. Structure of 200-nm Tc films.}

Optical microscope image of the film on a clean glass substrate $(\times 40$, polarized light) $(a)$.

Scanning microscope images of the film on a glass substrate covered with a thin carbon layer (an electron beam incidence angle of $45^{\circ}$ with respect to the film surface: film edge $(b)$, film center $(c)$. Scanning microscope image of the center of the film on a copper substrate $(d)$

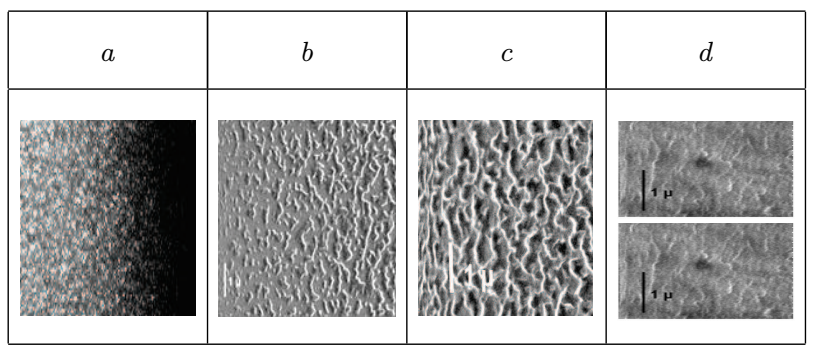


Table 2. Maximum positions $\boldsymbol{E}_{\boldsymbol{m}}$, widths $\boldsymbol{w}$, normalized amplitudes $\boldsymbol{D}_{m n}$,

and molecular vibration frequencies $\Delta E_{\nu}$ for the Gaussian components of the $S_{0} \rightarrow S_{1}$ transition in 200-nm Tc films on quartz and glass substrates at temperatures of 300 and $4.2 \mathrm{~K}$, respectively

\begin{tabular}{|c|c|c|c|c|c|c|c|c|}
\hline \multirow{2}{*}{ No. } & \multicolumn{4}{|c|}{$T_{s}=300 \mathrm{~K}$} & \multicolumn{4}{|c|}{$T_{s}=4.2 \mathrm{~K}[21]$} \\
\hline & $E_{m}, \mathrm{eV}$ & $w, \mathrm{eV}$ & $D_{m n}$, a.u. & $\Delta E_{\nu}, \mathrm{eV}$ & $E_{m}, \mathrm{eV}$ & $w, \mathrm{eV}$ & $D_{m n}$, a.u. & $\Delta E_{\nu}, \mathrm{eV}$ \\
\hline 1 & 2.332 & 0.0773 & 1.086 & & 2.361 & 0.0744 & 0.448 & \\
\hline 2 & 2.443 & 0.0670 & 1.383 & & 2.436 & 0.0794 & 0.736 & \\
\hline 3 & 2.600 & 0.1003 & 1.000 & & 2.605 & 0.1011 & 1.000 & \\
\hline 4 & 2.771 & 0.1025 & 0.536 & 0.171 & 2.786 & 0.1066 & 0.744 & 0.181 \\
\hline 5 & 2.904 & 0.1568 & 0.260 & 0.133 & 2.961 & 0.1116 & 0.460 & 0.165 \\
\hline 6 & 3.077 & 0.2424 & 0.146 & 0.173 & 3.142 & 0.1141 & 0.308 & 0.181 \\
\hline 7 & & & & & 3.317 & 0.1215 & 0.188 & 0.165 \\
\hline
\end{tabular}

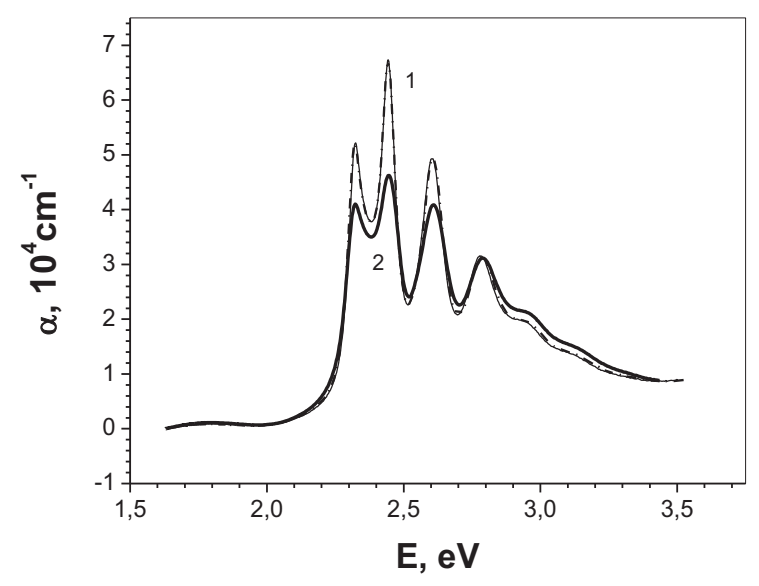

Fig. 1. Absorption spectra of 200-nm Tc films on quartz and glass substrates (1) and 120-nm Tc film on a glass substrate (2)

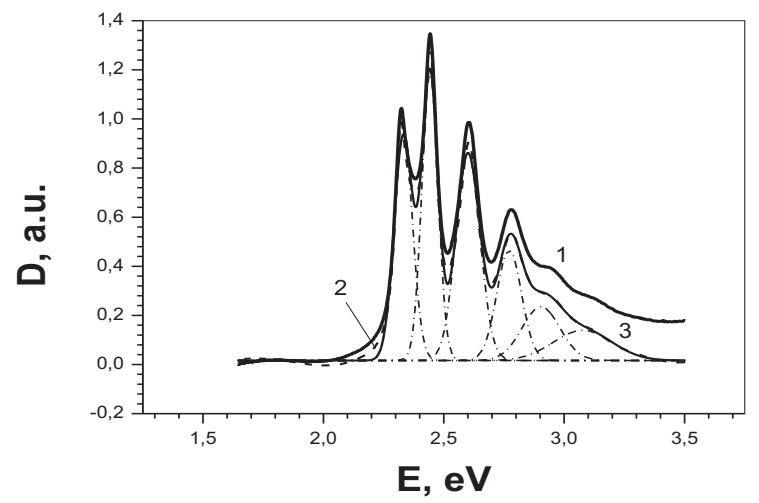

Fig. 2. Absorption spectra of 200-nm Tc films on a quartz substrate: initial (1), after subtracting the basis line (2), the sum of Gaussian components (3) (the first three long-wave maxima). Such variations of $\alpha$ may probably be associated with a stronger light scattering by Tc films, when their thicknesses grow. Accordingly, the intensity of light transmitted by the film decreases, and the magnitude of $\alpha$ increases. This effect is more considerable in the intervals, where the absorption is strong.

The intense absorption by polycrystalline Tc films $200 \mathrm{~nm}$ in thickness in the spectral interval $E>$ $>3.5 \mathrm{eV}$ gives a contribution to the long-wave vibronic band (Fig. 2, curve 1). This contribution was compensated using the method of base line subtraction from the initial spectrum (curve 1). The obtained spectrum (curve 2) was resolved into Gaussian components. Their sum (curve 3) correlates with curve 2. The analysis of the tabulated results of calculations shows that the reduced $\chi$-square error and the adjusted $R$-square coefficient of determination are equal to $5.844 \times 10^{-4}$ and 0.994 , respectively, with the relative determination errors for the energy maximum, the width of the Gaussian components, and its area not exceeding $0.05 \%, 1.0 \%$, and $1.0 \%$, respectively. Our calculations of the relative errors for the peak intensities of separate maxima (curves 2 and 3 ) showed that it did not exceed $5.5 \%$.

The obtained data are compared with the results of the Gaussian resolution of the long-wave vibronic absorption band measured for amorphous Tc films [21]. Table 2 contains the parameters of Gaussian components in the absorption spectra of polycrystalline 200$\mathrm{nm}$ Tc films. The films were sputtered onto quartz substrates with the temperature $T_{s}=300 \mathrm{~K}=T_{r}$, where $T_{r}$ is the temperature of absorption spectrum 
registration. The first two Gaussian components with maxima at 2.332 and $2.443 \mathrm{eV}$ were identified as components of the Davydov splitting of the $E_{\mathrm{D}}$ band of the $0 \rightarrow 0$ transition. This splitting was observed earlier for the absorption spectra of amorphous Tc films $200 \mathrm{~nm}$ in thickness, which were sputtered in the vacuum onto glass substrates with $T_{s}=4.2 \mathrm{~K}=T_{r}$ [21], and Tc single crystals [22]. The next four Gaussian components with maxima at 2.600, 2.771, 2.904, and $3.077 \mathrm{eV}$ can be classified as a vibronic progression of the $S_{0} \rightarrow S_{1}$ transition ( $0 \rightarrow n$ transitions, where $n=1,2,3,4)$. The energy distances between the maxima of the second and first, the fourth and third, and the third and second components amount to 0.171, 0.173 , and $0.133 \mathrm{eV}$, respectively. Hence, in the band of the $S_{0} \rightarrow S_{1}$ transition in polycrystalline Tc films, there emerge the peaks of intramolecular vibrations with average frequencies of $0.172 \mathrm{eV}\left(1387 \mathrm{~cm}^{-1}\right)$ and $0.133 \mathrm{eV}\left(1073 \mathrm{~cm}^{-1}\right)$.

When the free surfaces of the 120- and 200-nm Tc films were illuminated through the front ITO electrode and a teflon layer in air at a pressure of $10^{5} \mathrm{~Pa}$, the spectra of the front photo-emf $V_{\mathrm{f}}$ (Fig. 3, curves 1 and 4 , respectively) correlated with the absorption spectra (curve 3 ), and $V_{\mathrm{f}}$ was negative in the spectral interval of 1.657-3.258 eV for both films. The photovoltaic response of the $120-\mathrm{nm}$ film was more intense, and only the short-wave component of the Davydov splitting at $2.443 \mathrm{eV}$ manifested itself in the $V_{\mathrm{f}}$-spectra. At the same time, the vibronic bands of the $0 \rightarrow 1$ and $0 \rightarrow 2$ transitions in the thinner Tc film (curve 1) with maxima at 2.624 and $2.835 \mathrm{eV}$ turned out shifted toward short waves (hypsochromically) if compared with their counterparts in the absorption spectrum (curve 3). The band of the $0 \rightarrow 2$ transition did not manifest itself in the $V_{\mathrm{f}}$-spectrum of the 200-nm Tc film (curve 4). In addition, the $V_{\mathrm{f}}$-spectra of both films reveal long-wave low-intensive bands at 1.86 and $2.20 \mathrm{eV}$. The reduction of the air pressure in the measurement cell to $10^{2} \mathrm{~Pa}$ resulted in a decrease of the peak intensities of the bands at 2.624 and $2.835 \mathrm{eV}$ in the $V_{\mathrm{f}}$-spectra of a thin Tc film (curve 2) in comparison with those obtained at an air pressure of $10^{5} \mathrm{~Pa}$ (curve 1 ).

At the illumination of the 200-nm Tc film surface through the rear ITO electrode, which directly contacted with the film surface, the rear photo-emf $V_{\mathrm{r}}$ did not change the sign (Fig. 4, curve 4), being positive in the interval of $1.657-3.258 \mathrm{eV}$. However, a

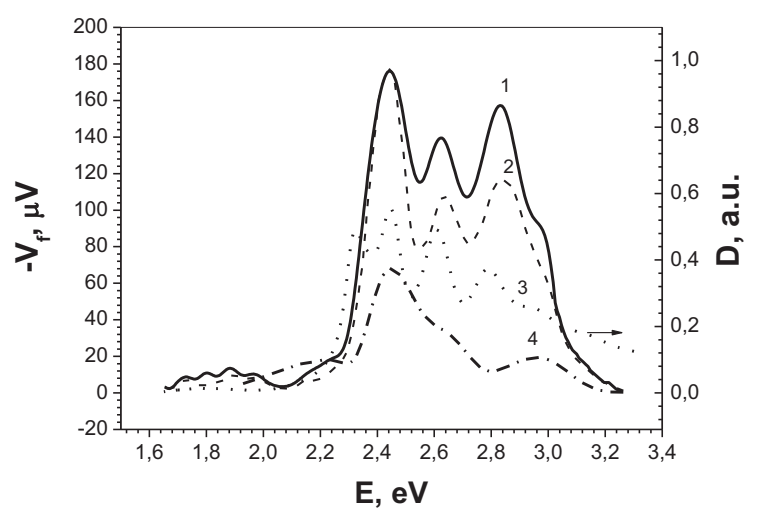

Fig. 3. Spectra of the frontal condenser photo-emf in the 120nm (1 and 2) and 200-nm (4) Tc films, and absorption spectrum of a $120-\mathrm{nm}$ Tc film (3). Curves 1 and 4 were registered at an air pressure of $10^{3} \mathrm{~Pa}$, and curve 2 at $10^{2} \mathrm{~Pa}$

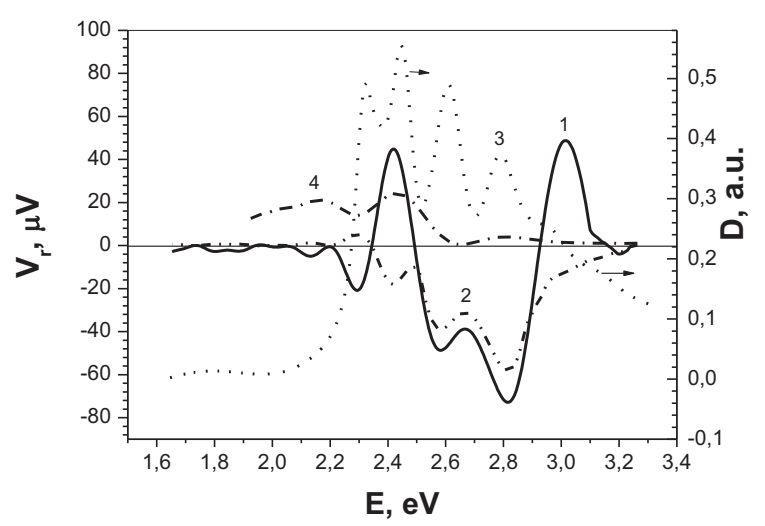

Fig. 4. Spectra of the rear capacitor photo-emf in Tc films. Notations are the same as in Fig. 3

new long-wave band at $2.171 \mathrm{eV}$ was observed, which was absent in the absorption spectrum. At the same time, the rear photo-emf $V_{r}$ of the $120-\mathrm{nm}$ Tc film changed its sign (Fig. 4, curve 1). It was negative in the intervals of $2.197-2.341 \mathrm{eV}$ and $2.494-2.927 \mathrm{eV}$ and positive in the intervals of $2.341-2.494 \mathrm{eV}$ and 2.927-3.153 eV. A similar spectrum of the photovoltaic response was observed in work [4], in which Tc single crystals $50-100 \mu \mathrm{m}$ in thickness were illuminated with non-modulated light through translucent Ag electrodes. As the air pressure in the measurement cell was diminished to $10^{2} \mathrm{~Pa}$, the inversion of the sign and the peak intensity for $V_{\mathrm{r}}$ was observed in the thinner Tc film (Fig. 4, curve 2) in the intervals of 2.197-2.341 eV, 2.341-2.494 eV, and $2.927-3.153 \mathrm{eV}$, 
and a reduction of the peak intensities for the bands at 2.581 and $2.811 \mathrm{eV}$.

\section{Discussion of Experimental Results}

The analysis of the microscopy data reported above shows that the structure of Tc films depends on the type of substrates used for the film sputtering. Polycrystalline films are formed on glass substrates at $T_{s}=300 \mathrm{~K}$, as well as on clean substrates or substrates covered with carbon and ITO layers, which agrees with the results of work [23]. Distinctions between the structures of Tc films on glass and copper substrates can be explained by different intensities of the interaction between Tc molecules themselves and their interaction with molecules in the substrate and in the thin carbon and ITO layers. In the case of glass substrates, the interaction of Tc molecules with one another prevails, which results in the formation of "island" Tc films in the course of sputtering. The interaction between $\mathrm{Tc}$ molecules and $\mathrm{Cu}$ atoms prevails on copper substrates, which is responsible for the initial formation of continuous Tc films with relatively large crystallites on the substrate. On the surface of those crystallites, there arise submicronic crystallites, the appearance of which is associated only with the interaction of Tc molecules with one another.

It was found [21] that amorphous Tc films consist of the amorphous and crystalline phases, which are a result of the long- and short-range intermolecular interactions, respectively. The presence of the crystalline phase in those films makes it possible to assert that they should rather be called quasi-amorphous. In Table 2, the parameters of Gaussian components for polycrystalline and quasi-amorphous Tc films are quoted. The Gaussian components are described by the formula

$D_{n}=D_{n m} e^{-\frac{2\left(E-E_{m}\right)^{2}}{w^{2}}}$,

where $D_{n}$ and $D_{n m}$ are the current and peak optical densities, respectively, normalized to the amplitude value $D_{m}$ for the band of the $0 \rightarrow 1$ transition in Tc films; $E$ and $E_{m}$ are the quantum energies for $D_{n}$ and $D_{n m}$, respectively; and $w$ is the width of the Gaussian band, which is related to the full width at a half maximum FWHM by the formula FWHM $\approx$ $\approx 1.1774 w$.

The analysis of those data shows that the crystalline phase manifests itself in the absorption spec- tra of quasi-amorphous films as the components of the Davydov splitting of the $0 \rightarrow 0$ band corresponding to the first singlet transition in a Tc molecule with maxima at 2.361 and $2.436 \mathrm{eV}$. The corresponding frequencies of intramolecular vibrations in those films amount to $0.181 \mathrm{eV}\left(1460 \mathrm{~cm}^{-1}\right)$ and $0.165 \mathrm{eV}\left(1331 \mathrm{~cm}^{-1}\right)$. The indicated values are larger than their counterparts for polycrystalline Tc films: $0.172 \mathrm{eV}\left(1387 \mathrm{~cm}^{-1}\right)$ and $0.133 \mathrm{eV}\left(1073 \mathrm{~cm}^{-1}\right)$, respectively. The $0.181-\mathrm{eV}$ and $0.172-\mathrm{eV}$ vibrational modes are close by energy to the completely symmetric $0.177-\mathrm{eV}$ vibration mode $\left(1428 \mathrm{~cm}^{-1}\right)$ of $\mathrm{C}-\mathrm{C}$ bonds in free Tc molecules [24]. The nature of vibrational modes with frequencies of 1331 and $1073 \mathrm{~cm}^{-1}$ remains still unknown. In work [25], the modes with close frequencies (1382 and about $1000 \mathrm{~cm}^{-1}$ ) were observed in the infra-red absorption spectrum of a polycrystalline Tc powder pressed in KBr pellets, and those modes were supposed to be associated with deformation vibrations of $\mathrm{C}-\mathrm{C}$ and $\mathrm{C}-\mathrm{H}$ bonds in $\mathrm{Tc}$ molecules.

The dominant role in the formation of spectral curves is played by the probability distribution for transitions from the given vibrational level of the initial state onto various vibrational levels of the final electronic state (the configurational distribution), which is determined by the Franck-Condon principle [26]. McCoy and Ross [27] used a harmonic oscillator model in the Franck-Condon approximation for the spectra of aromatic molecules with a pronounced vibrational structure and obtained a simple expression for the case of absorption:

$\frac{I_{n}}{I_{0}}=\frac{E_{m n}}{E_{m 0}} \frac{z^{n}}{n !}$,

where $I_{0}$ and $I_{n}$ are the intensities of the bands with the energies $E_{m 0}$ and $E_{m n}$, respectively; the parameter $z$ is the ratio between the potential energy of an elastic deformation of the molecule at its excitation and the energy $\Delta E_{\nu}$ of completely symmetric vibrations, which manifests itself most intensively in the electron spectrum:

$z=\frac{k(\Delta Q)^{2}}{2\left(\Delta E_{\nu}\right)}$

$k$ is the force constant for the bonds forming the molecular backbone; and $\Delta Q$ is a shift of the configuration coordinate of a molecule at its excitation. For

ISSN 2071-0186. Ukr. J. Phys. 2016. Vol. 61, No. 1 
Table 3. Values of Davydov splitting components $\boldsymbol{E}_{+}$and $\boldsymbol{E}_{-}$, splitting

amplitude $\Delta E_{\mathrm{D}}$, and resonance interaction term $L_{11}$ in Tc crystals and polycrystalline and quasi-amorphous Tc films at temperatures of 300 and $4.2 \mathrm{~K}$

\begin{tabular}{|c|c|c|c|c|c|c|c|c|c|c|c|}
\hline \multirow{2}{*}{ No. } & \multicolumn{5}{|c|}{$T_{s}=300 \mathrm{~K}$} & \multicolumn{5}{c|}{$T_{s}=4.2 \mathrm{~K}$} & \multirow{2}{*}{ Source } \\
\cline { 2 - 12 } & $E_{+}, \mathrm{eV}$ & $E_{-}, \mathrm{eV}$ & $\Delta E_{\mathrm{D}}, \mathrm{eV}$ & $\langle E\rangle, \mathrm{eV}$ & $L_{1} 1, \mathrm{eV}$ & $E_{+}, \mathrm{eV}$ & $E_{-}, \mathrm{eV}$ & $\Delta E_{\mathrm{D}}, \mathrm{eV}$ & $\langle E\rangle, \mathrm{eV}$ & $L_{1} 1, \mathrm{eV}$ & \\
\hline 1 & 2.358 & 2.445 & 0.087 & 2.402 & 0.026 & 2.318 & 2.433 & 0.115 & 2.376 & 0.048 & {$[29]$} \\
2 & 2.366 & 2.440 & 0.074 & 2.403 & 0.025 & 2.317 & 2.429 & 0.112 & 2.373 & 0.051 & {$[22]$} \\
3 & 2.357 & 2.433 & 0.076 & 2.395 & 0.033 & 2.317 & 2.440 & 0.123 & 2.379 & 0.045 & {$[22]$} \\
4 & 2.360 & 2.439 & 0.079 & 2.400 & 0.028 & 2.317 & 2.434 & 0.117 & 2.376 & 0.048 & \\
5 & & & & & & 2.361 & 2.436 & 0.075 & 2.399 & 0.025 & {$[21]$} \\
6 & 2.332 & 2.443 & 0.111 & 2.388 & 0.040 & & & & & & This work \\
\hline
\end{tabular}

multiatomic molecules, the quantity $\Delta Q$ is equal to the quadratic mean of length variations of all bonds in the backbone at the excitation. The value $k=$ $=750 \mathrm{~N} / \mathrm{m}$ was selected as for anthracene [27]. The intensity of the Gaussian band $I \sim D_{m n} w$, where $D_{m n}$ is the normalized optical density. The parameters $z$ and $\Delta Q$ were determined from expressions (2) and (3), respectively. On the basis of the data in Table 2 and the absorption spectra of Tc in benzene [28], the values of $z$ and $\Delta Q$ were found for Tc molecules in the polycrystalline Tc films $\left(\Delta E_{\nu}=\right.$ $=0.172 \mathrm{eV}, z=1.01$, and $\Delta Q=8.6 \mathrm{pm})$, the quasiamorphous Tc films $\left(\Delta E_{\nu}=0.181 \mathrm{eV}, z=1.60\right.$, and $\Delta Q=11.1 \mathrm{pm})$, and the Tc solution in benzene $\left(\Delta E_{\nu}=0.171 \mathrm{eV}, z=0.86\right.$, and $\left.\Delta Q=7.9 \mathrm{pm}\right)$. In such a way, the shift of configuration coordinate $\Delta Q$, which determines the intensity distribution of Gaussian components in the absorption spectra and a variation of the equilibrium distances between atoms at the excitation of Tc molecules, turned out the smallest in the benzene solution (free molecules) and the largest in the quasi-amorphous films. In the quasiamorphous films, the most intense is the band of the $0 \rightarrow 1$ transition with an energy of $2.605 \mathrm{eV}$. In the polycrystalline films and the benzene solutions, the intensity is maximum for the band associated with the short-wave component of the Davydov splitting and the band of the $0 \rightarrow 0$ transition with energies of 2.443 and $2.620 \mathrm{eV}$, respectively. Hence, Tc molecules in quasi-amorphous films sputtered onto substrates at $4.2 \mathrm{~K}$ and excited by light turned out deformed more strongly in comparison with those in polycrystalline films and with free molecules (in the benzene solution) at $300 \mathrm{~K}$.
Using formula (2), the positions and the peak intensities were determined for the bands corresponding to the $0 \rightarrow 0$ transition of Tc molecules in the polycrystalline $\left(E_{0}=2.428 \mathrm{eV}, D_{m 0}=1.38\right)$ and quasi-amorphous $\left(E_{0}=2.424 \mathrm{eV}, D_{m 0}=0.74\right)$ films, whose values are close to the corresponding values for the short-wave components of the Davydov splitting in those films (Table 2, row 2). On the basis of the data obtained, a variation of the interaction energy between an excited molecule and other molecules (the dispersion term $\Delta W$ ) was estimated as the difference between the $E_{0}$-values quoted above for the Tc films and the benzene Tc solution $\left(E_{0}=2.620 \mathrm{eV}\right)$. For the polycrystalline and quasi-amorphous films, the absolute value of $\Delta W$ amounts to 0.192 and $0.196 \mathrm{eV}$, respectively. These values are close to the value $\Delta W=$ $=0.200 \mathrm{eV}$ reported in work [24].

For Tc crystals with two nonequivalent molecules in a unit cell, there are two exciton bands of the first singlet state. If light falls normally to the plane $\mathbf{a b}$ of the crystal (the wave vector $\mathbf{k}=0$ ), the energies of those bands are determined by the formula [24]

$E_{ \pm}=E_{0}+\Delta W+L_{11} \pm L_{12}$

where $E_{0}=2.62 \mathrm{eV}$ is the excitation energy for an isolated Tc molecule, $\Delta W$ is the dispersion term considered above, and $L_{11}$ and $L_{12}$ are the terms of the resonance interaction between translationally equivalent and nonequivalent, respectively, molecules. Since the terms $\Delta W, L_{11}$, and $L_{12}$ are negative by value, $E_{-}>E_{+}$by magnitude. The difference between $E_{-}$ and $E_{+}$determines the value of Davydov splitting $\Delta E_{\mathrm{D}}$, which is twice as large as the absolute value of the term $L_{12}$. One-half of the sum $E_{-}+E_{+}$(the 
average value $\langle E\rangle)$ equals

$\langle E\rangle=E_{0}+\Delta W+L_{11}$.

This equation was used to determine the value of $L_{11}$. The values of $E_{-}, E_{+},\langle E\rangle, \Delta E_{\mathrm{D}}$, and the absolute values of $L_{11}$ are quoted in Table 3 . The tabulated data are obtained from the polarized reflection spectra of free crystals with the thicknesses $d>1 \mu \mathrm{m}$ (rows 1 and 2) and thin crystals with the thicknesses $d<1 \mu \mathrm{m}$ in the optical contact with quartz (row 3 ). It was found [22] that the positions of the maxima of polarized absorption and reflection bands for the thin Tc crystals $0.13 \mu \mathrm{m}$ in thickness coincide. If this coincidence is characteristic of free crystals as well, the data obtained for Tc crystals and films can be compared. In this case, it has to be taken into account that the values of $E_{-}$and $E_{+}$for the crystals correspond to the maxima of the $a$ - and $b$-components, respectively, of the Davydov splitting. Row 4 contains the average values for crystals, and rows 5 and 6 the average values for quasi-amorphous and polycrystalline films, respectively. The $E_{-}$-values for Tc crystals and films practically coincide at temperatures of 300 and $4.2 \mathrm{~K}$. Their average value equals $2.438 \mathrm{eV}$. The $E_{+}$-values differ more strongly. The value of $\Delta E_{\mathrm{D}}$ is higher for the polycrystalline films and lower for the quasi-amorphous ones in comparison with the values for crystals at temperatures 300 and $4.2 \mathrm{~K}$, respectively. In every case, the absolute value of $L_{12}$ is larger than $L_{1}$, i.e. the resonance interaction between translationally nonequivalent molecules is stronger than that between translationally equivalent ones.

Using the absorption spectra (Fig. 1), the light penetration length $L_{\alpha}$ was calculated, which determines the photogeneration region for nonequilibrium charge carriers and is reciprocal to $\alpha$. At the quantum energy $E=2.443 \mathrm{eV}$, its minimum value amounts to $214 \mathrm{~nm}$ for 120-nm Tc films (curve 2) and to $149 \mathrm{~nm}$ for 200-nm Tc films (curve 1). Hence, for a 120-nm Tc film, the penetration length $L_{\alpha}$ in the spectral interval of $1.6-3.5 \mathrm{eV}$ is larger than the film thickness $d$. The same relation between $L_{\alpha}$ and $d$ takes place for a 200-nm Tc film, except for a narrow spectral interval of $2.418-2.467 \mathrm{eV}$ and a maximum at $2.332 \mathrm{eV}$, where $L_{\alpha} \leq d$. This fact means that the photogeneration of nonequilibrium charge carriers in both Tc films, irrespective of their thickness, occurs simulta- neously near their free and rear surfaces, under both frontal and rear illumination.

On the basis of the Bouguer-Lampert-Beer law, a calculation of the relative absorbed light intensity in the Tc films, $\Delta I / I_{0}$, was carried out (here, $\Delta I$ and $I_{0}$ are the absorbed and initial, respectively, light intensities). It was found that, the 120- and 200-nm films absorb $39 \%$ and $66 \%$, respectively, of incident light in the interval of strong absorption (at a quantum energy of $2.422 \mathrm{eV}$ ) and $18 \%$ and $31 \%$, respectively, in the interval of weak absorption $(E=3.018 \mathrm{eV})$. At the rear illumination $(E=2.422 \mathrm{eV})$, the fractions of light absorbed in thin layers (each $20 \mathrm{~nm}$ in thickness) located immediately near the rear and free surfaces of the film amount to $10.3 \%$ and $3.9 \%$ in the case of a $200-\mathrm{nm}$ film, and $7.8 \%$ and $5.2 \%$ in the case of a $120-\mathrm{nm}$ film. In the interval of weak absorption $(E=3.018 \mathrm{eV})$, the corresponding values are almost identical for both films and equal, on the average, to about $3 \%$.

The parameter $V_{\mathrm{f}}$ is found negative at the illuminated free surface of both 120- and 200-nm Tc films, i.e. the photoconductivity in those films is of the $p$ type. The origin of $V_{\mathrm{f}}$ and its variations in the case where the Tc films $1.5-2.0 \mu \mathrm{m}$ in thickness were subjected to an external electric field and illuminated by light with a constant intensity are explained by a joint action of three components: the Dember (diffusion) photo-emf $V_{\mathrm{Df}}$ of the bulk nature, the surface-barrier photo-emf $V_{\mathrm{bf}}$, and the photo-emf $V_{\mathrm{tf}}$ emerging due to the separation of free carriers by the field in the space charge region and the capture of nonequilibrium charge carriers by donor or acceptor surface states, respectively [30]. In addition, the calculation showed that $V_{\mathrm{Df}} \sim \alpha$ in the case of monopolar photoconductivity, i.e. the $V_{\mathrm{Df}}$ and absorption spectra correlate [31]. The long-wave bands at 1.86 and $2.00 \mathrm{eV}$, and the correlations between the $V_{\mathrm{f}}$ (Fig. 3, curves 1 and 4 ) and absorption (Fig. 3, curve 3) spectra testify to the contribution of $V_{\mathrm{bf}}$ and $V_{\mathrm{Df}}$ to $V_{f}$ in the 120- and 200-nm Tc films.

It should be noted that the charge on the film surface affects the energy band bending. Therefore, in what follows, under the term $V_{\mathrm{b}}$ (front or rear), we will understand a resultant emf of the components $V_{\mathrm{b}}$ and $V_{\mathrm{t}}$. Since $V_{\mathrm{f}}$ does not change its sign in the long-wave spectral interval, the energy band bending at the free surface of Tc films is blocking for holes, which agrees with the results of work [30]. If the 
band bending $V_{\mathrm{br}}$ near the rear ITO electrode is also blocking, then $V_{\mathrm{f}}=V_{\mathrm{Df}}+V_{\mathrm{bf}}-V_{\mathrm{br}}$. In this case, the resulting flux of nonequilibrium holes associated with their diffusion $\left(V_{\mathrm{Df}}\right)$ and drift $\left(V_{\mathrm{bf}}-V_{\mathrm{br}}\right)$ will be directed from the free surface into the bulk of a Tc film toward the rear ITO electrode. Near the latter, the nonequilibrium holes recombine with electrons arriving from the external part of the circuit, and the free surface of the Tc film is charged negatively, whereas the front ITO electrode separated from it by a teflon film is charged positively. The magnitudes of those charges change with the modulation frequency of exciting light.

The spectrum of $V_{\mathrm{r}}$ (Fig. 4, curve 4) for a 200-nm Tc film is similar to the spectrum of $V_{\mathrm{f}}$ (Fig. 3, curve 4 ), i.e. the band bending near the rear ITO electrode is blocking, and $V_{\mathrm{r}}=V_{\mathrm{Dr}}+V_{\mathrm{br}}-V_{\mathrm{bf}}$, where the sign of $V_{\mathrm{Dr}}$ is opposite to that of $V_{\mathrm{Df}}$. In this case, the diffusion $\left(V_{\mathrm{Dr}}\right)$ and the drift $\left(V_{\mathrm{br}}-V_{\mathrm{bf}}\right)$ of nonequilibrium holes form their resulting flux toward the free surface and the appearance of a positive charge on it.

In a $120-\mathrm{nm}$ Tc film, the described processes take place in the interval of strong absorption (2.341$2.494 \mathrm{eV}$ ) (Fig. 4, curve 1). The rear $V_{\mathrm{r}}$ is positive in the interval of weak absorption $(2.927-3.153 \mathrm{eV})$ as well. Since the energy of light quanta in this interval is close to the Tc energy gap width $\left(E_{g} \approx 3.0 \mathrm{eV}\right.$ [1]), the positive sign of $V_{\mathrm{r}}$ can be a result of the contribution made by nonequilibrium electrons generated simultaneously with holes at the autoionization [32]. Near the ITO electrode, the band bending for those electrons is antiblocking, which stimulates their drift in the external electric circuit to the front ITO electrode and the appearance of a negative charge on it. Near the free surface, the nonequilibrium electrons recombine with the holes captured by the surface states. As a result, the positive surface charge and, consequently, the blocking band bending and $V_{\mathrm{bf}}$ decrease. If, besides that, $V_{\mathrm{Dr}}+V_{\mathrm{br}}>V_{\mathrm{bf}}$, then, in the spectral range of $2.927-3.153 \mathrm{eV}$, the resulting flux of nonequilibrium holes is directed to the free surface and leads to the appearance of a positive charge on it. In the spectral intervals of $2.197-2.341 \mathrm{eV}$ and 2.494-2.927 eV, the voltage $V_{r}<0$ (Fig. 4, curve 1 ), i.e. the free surface is charged negatively. In the case of hole photoconductivity, this is possible provided that $V_{\mathrm{Dr}}+V_{\mathrm{br}}<V_{\mathrm{bf}}$. In the interval of $2.197-2.341 \mathrm{eV}$, the absorption in a Tc film is weak, and the gradient of the nonequilibrium hole distribution in its bulk is insignificant, which results in a substantial reduction of $V_{\mathrm{Dr}}$. At $V_{\mathrm{Dr}} \approx 0$, the inequality presented above becomes simpler to $V_{\mathrm{br}}<V_{\mathrm{bf}}$, i.e. the band bending near the rear ITO electrode is smaller than that near the film free surface. In the interval of $2.494-2.927 \mathrm{eV}$, the growth of the absolute value of $V_{\mathrm{r}}$ is connected with the increase in the number of nonequilibrium holes, which is confirmed by a growth of the Tc film photoconductivity in this region [32]. At an energy of light quanta of 2.197-3.153 eV, the values of $V_{\mathrm{r}}$ and $V_{\mathrm{f}}$ substantially depend on the oxygen concentration (Figs. 3 and 4 , curves 2 and 1 ). Therefore, the indicated variations can also be associated with tetraoxotetracene (TOT), which is formed in the course of Tc film oxidation, and the emergence of charge-transfer complexes of the Tc-TOT or $\mathrm{Tc}-\mathrm{O}_{2}$ types [32].

\section{Conclusions}

The structure of thin Tc films with the thickness $d \leq 200 \mathrm{~nm}$ is governed by the interaction energy of Tc molecules with one another, $W_{1}$, and with the molecules of substrates and ITO layers, and carbon atoms on the surface of those substrates, $W_{2}$. In the course of thermal sputtering in vacuum onto copper $\left(W_{1}<W_{2}\right)$ and glass or quartz $\left(W_{1}>W_{2}\right)$ substrates, continuous or island, respectively, polycrystalline films are formed. In quasi-amorphous films at $4.2 \mathrm{~K}$, the Tc molecules excited by light are deformed more strongly in comparison with those in polycrystalline films and free molecules at $300 \mathrm{~K}$. In Tc single crystals and polycrystalline films, the absolute value of the energy $L_{12}$ is larger than $L_{11}$, i.e. the resonance interaction of translationally nonequivalent molecules with one another is stronger than between translationally equivalent molecules.

The photovoltaic response at the front, $V_{\mathrm{f}}$, and rear, $V_{\mathrm{r}}$, illuminations of Tc films with the thickness $d \leq 200 \mathrm{~nm}$ is the algebraic sum of three components: the diffusion (Dember) photo-emf of the bulk origin and the surface-barrier photo-emfs associated with the band bending at the free and rear surfaces of Tc films. In the spectral interval of $1.657-3.258 \mathrm{eV}$, the sign of $V_{\mathrm{f}}$ at the free surface of those films is negative, which testifies to their $p$-type photoconductivity. Moreover, $V_{\mathrm{r}}>0$ in the $200-\mathrm{nm}$ Tc film, i.e. its free surface is charged positively. The photo-emf $V_{\mathrm{r}}$ in the 120-nm Tc film changes its sign in the spectral intervals of $2.193-2.494 \mathrm{eV}$ and $2.927-3.153 \mathrm{eV}$ 
if the oxygen concentration in the measurement cell decreases, which testifies to a variation of the energy band bending in the Tc films near their rear and free surfaces.

The work was carried out in the framework of projects Nos. $14 \mathrm{~V} / 182$ and $14 \mathrm{VTs} / 157$ of the $\mathrm{Na}$ tional Academy of Sciences of Ukraine. The authors are thankful to the senior researchers V.I. Styopkin and A.B. Nych for studying the structure of Tc films on electron and optical microscopes, respectively.

1. N. Geacintov, M. Pope, and H. Kallman, J. Chem. Phys. 45, 2639 (1966).

2. A.K. Ghosh and T.Feng, J. Appl. Phys. 44, 2781 (1973).

3. R. Signerski, J. Kalinowski, I. Koropecky et al., Thin Solid Films 121, 175 (1984).

4. P.J. Reucroft, P.L. Kronick, and E.E. Hillman. Mol. Cryst. Liq. Cryst. 6, 247 (1969).

5. G. Horowitz. J. Mater. Res. 19, 1946 (2004).

6. F. Cicoira, C. Santato, F. Dinelli et al., Adv. Funct. Mater. 15, 375 (2005).

7. J.-M. Choi, J. Lee, D.K. Hwang et al., Appl. Phys. Lett. 88, 043508 (2006).

8. Y. Xia, V. Kalinari, and C.-D. Frislie. Appl. Phys. Lett. 90, 162106 (2007).

9. Md.M. Islam, J. Bangladesh Chem. Soc. 25, 194 (2012).

10. C.-T. Chien and C.-C. Lin, J. Mater. Chem. 22, 13070 (2012).

11. A. Hepp, H. Heil, W. Weise et al., Phys. Rev. Lett. 91, 157406 (2003).

12. C. Rostb, S.F. Kargb, and M.Muccini, Synth. Metals 146, 329 (2004).

13. J. Reynaert, D. Cheyns, D.Janssen et al., J. Appl. Phys. 97, 114501 (2005).

14. T. Takahashi, T. Takenobu, J. Takeya et al., Adv. Funct. Mater. 17, 1623 (2007).

15. Y. Ohshima, H. Satou, N. Hirako et al., Jpn. J. Appl. Phys. 50, 04DK14 (2011).

16. C.-W. Chu, Y. Shao, V. Shrotriya et al., Appl. Phys. Lett. 86, 243506 (2005).

17. Y. Shao, S. Sista, C.-W. Chu et al., Appl. Phys. Lett. 90, 103501 (2007).

18. R.J. Tseng, R. Chan, V.C. Tung et al., Adv. Mater. 20, 435 (2008).

19. R. Signerski. Mater. Sci. Poland 27, 763 (2009).

20. M.P. Gorishnyi, A.V. Verbitsky, A.V. Kovalchuk et al., Semicond. Phys. Quant. Electr. Optoelectr. 11, No. 3, 236 (2008).

21. R. Jankowiak, K.D. Rockwitz, and H. Bässler, J. Phys. Chem. 87, 552 (1983).

22. D.D. Kolendritskii, M.V. Kurik, and Yu.P. Pirjatinskii, Phys. Status Solidi B 91, 741 (1979).
23. W. Riemer and J.V. Hardy, Phys. Status Solidi A 14, 473 (1972).

24. E.I. Silins, M.V. Kurik, and V. Capek, Electronic Processes in Organic Molecular Crystals. Localization and Polarization Phenomena (Zinatne, Riga, 1988) (in Russian).

25. L. Viduta, T. Gavrilko, A. Marchenko et al., Ukr. J. Phys. 57, 260 (2012).

26. G. Herzberg, Molecular Spectra and Molecular Structure I: Spectra of Diatomic Molecules (Van Nostrand, New York, 1950).

27. E.F. McCoy and I.G. Ross, Austr. J. Chem. 15, 573 (1963).

28. M.P. Gorishnyi, M.V. Kurik, and L. Libera, Ukr. Fiz. Zh. 32, 1013 (1987).

29. J.M. Turlet and M.R. Philpott, J. Chem. Phys. 62, 4260 (1975).

30. Yu.M. Lopatkin, Research of the Processes of Information Reflection in Linear Polyacetate Films, Ph.D. thesis (Kyiv, 1982) (in Russian).

31. M.P. Gorishnyi, Ukr. Fiz. Zh. 52, 1154 (2007).

32. Ya.I. Vertsymakha and Yu.M. Lopatkin, in Fundamentals of Optical Memory and Medium, No. 15 (1984), p. 49 (in Russian).

Received 20.04.15.

Translated from Ukrainian by O.I. Voitenko

М.П. Горішний, А.Б. Вербицъкий

СТРУКТУРА, ОПТИЧНІ

І ФОТОВОЛЬТАЇЧНІ ВЛАСТИВОСТІ

ТОНКИХ ПЛІВОК ТЕТРАЦЕНУ

$\mathrm{P}$ е $з$ ю м е

Досліджено структуру, спектри поглинання і фотовольтаїчний відгук тонких плівок тетрацену (Тc) товщинами 120 i 200 нм, напорошених у вакуумі 6,5 мПа на різні підкладки при кімнатній температурі. Фотовольтаїчний відгук виміряно конденсаторним методом. Встановлено, що на скляних і кварцових підкладках утворюються острівцеві, а на мідних - суцільні полікристалічні плівки, що зумовлено різними величинами енергії взаємодії молекул Тс між собою та із молекулами підкладок, шарів ITO та атомами карбону на поверхні цих підкладок. В квазіаморфних плівках збуджені світлом молекули Тс при 4,2 K деформуються сильніше порівняно із такими у полікристалічних плівках і вільними молекулами при $300 \mathrm{~K}$.

У спектральному діапазоні 1,637-3,258 еВ знак фронтальної конденсаторної фото-ерс на освітленій вільній поверхні плівок Тс від'ємний, що свідчить про їх діркову фотопровідність. Тильна фото-ерс плівок Тс товщиною 120 нм (освітлення через ITО-електрод, який безпосередньо контактує із плівкою Тс) змінює свій знак у спектральних областях 2,193-2,494 і 2,927-3,153 еВ при зменшенні концентрації кисню у вимірювальній комірці, що свідчить про зміну величини вигинів енергетичних зон Тс біля тильної і вільної поверхонь цих плівок. 